Annales UMCS

Informatica

Lublin-Polonia

Sectio AI

http://www.annales.umcs.lublin.pl/

\title{
The role of the students' and teachers' activities in the adoption and continued use of an e-learning platform
}

\author{
Tomasz Walczyński*, Beata Bylina, Jarosław Bylina \\ Institute of Mathematics, University of Maria Curie-Skłodowska, \\ pl. M. Curie-Sklodowskiej 5, 20-031 Lublin, Poland.
}

\begin{abstract}
This paper identifies and examines an impact of students' and teachers' activities on possibility of using and adapting e-learning platform in postgraduate studies. The paper aims at experimental survey of students' satisfaction level, their opinions concerning implementing e-learning at work as well as correlation students' activity, teachers' activity and e-learning results. Our hypotheses are tested with 160 students of postgraduate studies using e-learning educational platform.
\end{abstract}

\section{Introduction}

The development of new technologies is followed by their progressing influence on all forms of human activity including education. Rapid development of information and communicative technologies involves the development of educational new techniques and methods, for example e-learning (on-line learning).

E-learning problem is a very important issue from the viewpoint of various areas: economics, education, sociology, psychology and computer science. E-learning problems concern many aspects beginning with students' motivation and ending in psychological aspects [1], functionality as well as opportunity to develop a given information system.

*twalczyn@hektor.umcs.lublin.pl 
From the informational point of view e-learning reality is based upon certain CMS which disposes with some functionalities, opportunities and effectiveness to mange with educational process efficiently. Moodle [3] is an example of a free CMS platform.

Taking into account possible development of educational platforms functionality to gain new opportunities or progress existing activities, it is necessary to examine the level of students' satisfaction as well as the role and impact of different activities, the components of a given course on the knowledge level. Paper [2] empirically examined an impact of interactive video on student's teaching results and the level of student's satisfaction using some e-learning tools. The conclusion suggests that educational platforms should create opportunities to apply interactive video instructions which is a very important element.

The authors of this paper experimentally examine an impact of e-learning education on students' satisfaction level (adults) and also on an opportunity to implement elearning in their work places. Another issue surveyed by the authors is searching for correlations between students' and teachers' activities as well as an impact of those factors on knowledge acquisition.

The survey was conducted for 160 adult students of postgraduate studies at Maria Cure-Sklodowska University in Lublin with consortium of Warsaw University concering "Preparation of teaching staff for e-learning continuous education".

Section 2 describes theoretical background, survey model and hypothesis. Section 3 deals with methodology, Section 4 contains results interpretation and Section 5 conclusions.

\section{Survey methods and theoretical background}

The survey was conducted using the sample of 160 adult students ( age 25-62) of the postgraduate studies. The student groups of the postgraduate studies were:

- Teachers of different specializations: from schools for adults, continuous education centers and practical education centers;

- Teachers - consultants from Centers of Teachers' Education;

- Methodical advisors;

- Pedagogical staff from schools for adults and continuous education centers;

- Teachers employed in public schools.

During the project accomplishment the university provided students with access to:

- Two e-learning platforms. The first platform conducted 8 on-line courses and communicative forum via- the internet (for teacher-student contact) as well as communicative forum accessible to all students and teachers. The other platform was for students and it had character of the area where students developed their own courses (they had rights to develop courses), for example courses during learning the subject "Information educational tools" and had to pass the courses necessary to complete study. 
- Disk area to treasure materials created by groups or individuals (both during on-line classes and traditional ones).

Materials and teaching aids were collected in knowledge base which was accessible via the above mentioned educational platforms. All problems discussed during both stationary and on-line courses were widely documented on the educational platform. Material contents were richer than direct demands to pass a given subject. The questions asked on the internet forum and chats allowed to presume that a large number of students eagerly used the expanded knowledge contents. On-line courses lasted 185 hours which makes $66 \%$ of all courses but the traditional method took 95 hours. In semester II e-learning educational techniques were used in $80 \%$.

\subsection{Applied educational methods and activities}

During the e-learning education the following methods were used:

- Lecture, aiming at acquainting students with basic information concerning a given problem. During the courses, 46 lectures were available for students which accounted $23 \%$ of all components number.

- Discussion forum accessible on platform in every course. There were forums with the moderator where moderators answered students' questions or informed about the subject organization and there were educational forums during which students were to express their opinions about the subject proposed by the mentor. The internet forums registered over 10910 questions and answers between students and mentors. Forum was a component used very eagerly and accounted about $36 \%$ of all components number.

- Quizes (tests) - to examine knowledge. During the education process 37 tests were done which accounted $19 \%$ of all components number.

- Assignments pointed in picking up of practical skills. The task comprised three stages: preparing the contents by the teacher and putting task on the platform, solving off-line by students and putting file with the answer on the platform and the last stage- checking and marking the tasks by teachers. 31 tasks were done which accounted $16 \%$ of all components number.

- Other activities like; chat, voting, notions vocabulary. Chats allowed to communicate students with mentors. These chats were very intensive and students could obtain answers to their questions concerning material accomplishment especially at the beginning of study in "Introduction to e-learning education" where communication through chats was very intensive late in the evening. The number of all entries - 13860. Voting allowed to fix chat hours by teachers. Notions were prepared by teachers for students to facilitate and accelerate learning. The components called "others" accounted $6 \%$ of all.

- Consultations via e-mails on the educational platform - through that information channel students could ask questions and obtain answers. The 
number of e-mails on the educational platform was 6982 which means that every student wrote on the average 43 e-mails. It is impossible to count the number of e-mails written by students to teachers using private e-mail boxes.

- During the study over 55349 entries were registered. That number means logging on the average once a day.

\subsection{Hypotheses}

Interesting hypotheses are formulated in the following way:

H1: The level of students' satisfaction shows proper use and adaptation of e-learning educational platform. H2: The postgraduate study participants (owning to the acquired knowledge and skills) notice the necessity and opportunity of implementing e-learning in their own work environment H3: Teachers' activity influences the education results. H4: The higher level of participants' activity on the e-learning platform, the better education results.

\section{Survey methodology}

Questionnaires were used to examine an impact of education form on students' satisfaction level. Questionnaires were complated by students at the end of III semester (the last one). Students answered the questions as follows: "What extend did e-learning education satisfy you to?" (respondents could choose on the scale one of the answers; "didn't satisfy", "little", "rather", "satisfied") and also "Did participation in the postgraduate study and tasks accomplishment influence your opinion towards e-learning education?" (respondents could choose one of the following answers: "my enthusiasm rose", "my enthusiasm dropped", "it didn't have any impact on my attitude").

The authors used the questionnaires to examine an opportunity to apply and adapt the e-learning platform by students in their work environment. Their respondents had to answer the question " How do you estimate the chances of e-learning implementation in your work environment, at school, center?" (respondents could choose one of answers; "very good", "good", "rather good", "small", "rather small", "very amall", "difficult to say").

Then activities of students and teachers were read directly from the Moodle platform statistics. The first part of the data making the basis of survey includes both partial and final grades (resulting from the sum of partial grades) put on the platform. The full grades list is accessible in every course through the reference "Grades" and next clicking "Download in ODS format" in the format of spread sheet - OASIS - Open Document Format for Office Applications - ODS files Other formats are also accessible - text format or MS Excel sheet.

The other data which were used in the survey are collected during the Moodle service work in the form of logs in the data base in the table mdl_log. All detailed information 
about each activity of the user is collected here and is accessible through direct access to the data base through properly written SELECT queries of the language SQL.

The other data which were used in the survey are collected during the Moodle service work in the form of logs in the data base in the table mdl_log. All detailed information about each activity of the user is collected here and is accessible through direct access to the data base through properly written SELECT queries of the language SQL.

One subject from every semester was chosen to survey:

- "Introduction to e-learning education (WdKnO)" (I semester, 30 hours),

- "Formulating of multi-medial materials (OMM)" (II semester, 60 hours),

- "Organization of e-learning education process (OPKnO) (III semester, 30 hours).

The above mentioned subjects were chosen for the survey because they were in majority accomplished by e-learning.. For every course there were calculated the following characteristics of students' and teachers' activities (number of clicks during subject accomplishment): mean values, standard devotions (SD), sum, minimum, maximum, quartile 1 (Q1), median, quartile 3 (Q3) in Statistica 8.0 program based upon the data generated in files in the ODS format.

Moreover the program Statistica 8.0 was used to calculate the Pearson's correlation coefficients between the students' activity and the education results and next their relevance was surveyed using Student t test.

\section{Results analysis}

The truth of hypothesis H1 (The level of students' satisfaction shows the right use and adaptation of e-learning platform) is confirmed based upon students' answers to the question, "What extent did e-learning education satisfy you?" $80 \%$ of respondents were fully satisfied participating in the postgraduate study using the e-learning platform (60\% chose the answer "satisfied", $20 \%$ chose "very satisfied", 19\% - "rather satisfied" and only 1\% ( 1 student) - "small satisfied". That thesis is acknowledged by the students' answers the following question; "Did participation in the postgraduate study and tasks accomplishment influence your opinion towards e-learning education?". For $78 \%$ of the respondents, participation in the e-learning education meant growth of enthusiastic attitudes towards this kind of education, for $15 \%$ e-learning had no impact on their attitudes but only $7 \%$ of the respondents were not satisfied.

The truth of hypothesis H2 (Postgraduate study participants based on the acquired knowledge notice the necessity and opportunity to implement e-learning in their work environments) is confirmed based upon the students' answers to the question "How do you estimate the chances of e-learning implementation in your work environment, at school, center?" $69 \%$ of the respondents chose the answer "rather good" or "very good" concerning the e-learning implementation in their environments, $42 \%$ of the respondents chose the answer "rather good", 17\% - "good" and 10\% - "very good", $26 \%$ - "small" or "rather small" but the other 5\%- chose the answer -"very small". 
Pobrane z czasopisma Annales AI- Informatica http://ai.annales.umcs.pl

Data: 26/04/2023 13:29:21

The truth of hypothesis H3 (Students' activity influences education results) is confirmed based upon the answers to the open question: "What were you motivated by to undertake e-learning study?" About 38\% (most students) of the respondents mentioned teacher kindness and professionalism as enhancing and giving satisfaction factors. Table 1 presents the characteristics of teachers' activities compareed to those of students' activities based on some subject examples.

Table 1. Results from the models compared to the EM clustering.

\begin{tabular}{|l|l|l|l|l|l|l|l|l|l|l|}
\hline Subject & $\begin{array}{l}\text { Person } \\
\text { number }\end{array}$ & Mean & SD & Sum & Min & Max & Q1 & Median & Q3 \\
\hline \multirow{2}{*}{ WdKnO } & Students & 160 & 925 & 697 & 147985 & 98 & 4325 & 494 & 729 & 1137 \\
\cline { 2 - 11 } & Teachers & 3 & 8677 & 5866 & 26030 & 2243 & 13729 & 2243 & 10058 & 13729 \\
\hline \multirow{2}{*}{ OMM } & Students & 156 & 568 & 287 & 88564 & 74 & 1914 & 390 & 507 & 693 \\
\cline { 2 - 11 } & Teachers & 6 & 2592 & 1275 & 15551 & 1830 & 5161 & 1914 & 2135 & 2376 \\
\hline \multirow{2}{*}{ OPKnO } & Students & 149 & 361 & 221 & 53863 & 31 & 1494 & 225 & 312 & 437 \\
\cline { 2 - 11 } & Teachers & 4 & 2704 & 1445 & 10816 & 1404 & 4766 & 1803 & 2323 & 3605 \\
\hline
\end{tabular}

We can notice great differences among students' activities (e.g. the smallest value for WdKnO accounted 98 and the largest - 4325) and also among teachers' activities which was influenced by the number of on-line laboratories conducted by teachers, for example one of the teachers conducted simultaneously the on-line lecture (put the prepared materials and elaborated task on the platform). As far as the WdKnO course is concerned, 1 teacher's activity fell on the average 5.69 student's activities, as for the OMM and OPKnO courses, 5.70 and 4.98 student's activities respectively. It should be noted that teacher's activities influenced the student's activities having impact on education effects which will be shown in hypothesis $\mathrm{H} 4$.

The truth of hypothesis H4 (The larger student's activity on the educational platform, the best education results) is confirmed based upon large (larger than 0.5) and significantly larger than the zero Pearson's correlation coefficients. For the WdKnO course, the Pearson's correlation coefficient between the student's activities (clicks number) and the education effects (final points) accounted 0.52 and based upon t-student test that coefficient appeared to be significantly different (larger) than zero ( computer significance level $\mathrm{p}<0.0000$ ). A similar value (coincidence or dependence?) was obtained for the Pearson's correlation coefficients for the other subjects: OMM - 0.52, OPKnO - 0.53 which appeared to be statistically significant (n both examples: $\mathrm{p}<0.0000$ ). Additionally, the coefficients were calculated (correlation coefficient square), for $\mathrm{WdKnO}-0.279$ (it means that education efforts in $27 \%$ were explained by student's activities), for OMM and OPKnO-0.27 and 0.29 respectively. As follows from the survey results with very active persons characterized with very high grades high education effects could be obtained at average activity, so correlation between the activity and the education effects appeared only large, not very large (larger than 0.7). 


\section{Conclusions}

The results of survey show that the e-learning educational platform can be adapted to continuous education of adults which is confirmed by students' satisfaction level as well as their intentions to adapt e-learning in their work environments. E-learning platform influences positively education effects, especially teacher's kindness and professionalism enhance students' activity.

The educational platform Moodle would be worth expanding by statistics concerning teachers' activities and useful data like: logs number, sent mails number, materials number, answers number on forums and a number of checked tasks off-line.

\section{References}

[1] Wan Z., Wang Y., Haggerty N., Why people benefit from e-learning differently: The effects of psychological processes on e-learning outcomes, Information \& Management 45 (2008): 513-521.

[2] Zhang D., Zhou L., Briggs R. O., Nunamaker Jr. J. F., Instructional video in e-learning: assessing the impact of interactive video on learning effectiveness, Information \& Management 43 (2006): 15-27.

[3] http://moodle.org. 